\title{
The functional importance of the $\mathrm{N}$-terminal region of human Prolylcarboxypeptidase
}

\author{
J Mallela $^{1,2}$, R Perkins ${ }^{1}$, J Yang ${ }^{1}$, S Pedigo ${ }^{3}$, J Rimoldi ${ }^{4}$, and Z Shariat-Madar ${ }^{1,2, \ddagger}$ \\ 1 Department of Pharmacology, University of Mississippi, University, MS 38677-1848 \\ 2 Research Institute of Pharmaceutical Sciences, University of Mississippi, University, MS 38677-1848 \\ 3 Department of Chemistry \& Biochemistry, University of Mississippi, University, MS 38677-1848 \\ 4 Department of Medicinal Chemistry, University of Mississippi, University, MS 38677-1848
}

\begin{abstract}
The renin-angiotensin-system cascade pathway generates the vasopressor and prothrombotic hormones, angiotensin II (Ang II) and angiotensin III (Ang III) from angiotensinogen. One of the key enzymes for the generation of angiotensin 1-7 (Ang 1-7) and angiotensin 2-7 (Ang 2-7) from Ang II and III respectively, is prolylcarboxypeptidase (PRCP). To understand the contribution of the $\mathrm{N}$-terminal region to catalysis, an $\mathrm{N}$-terminal truncated form, lacking $179 \mathrm{~N}$-terminal residues of PRCP $\left(\mathrm{rPRCP}_{40}\right)$ were constructed. The circular dichroism $(\mathrm{CD})$ spectrum of $\mathrm{rPRCP}_{40}$ illustrated that it was structured with significant helical content as indicated by local minima at $\sim 220$ and 208 $\mathrm{nm}$. The main products of Ang III metabolized by $\mathrm{rPRCP}_{40}$ were Ang 2-7 plus phenylalanine as determined by LC-MS. Angiotensin I (Ang I) blocked the metabolism of Ang III by $\mathrm{rPRCP}_{40}$. These investigations showed that the C-terminal region of the $\mathrm{rPRCP}_{40}$ contributes to PRCP's catalytic function, and provided additional experimental evidence for this suggestion.
\end{abstract}

\section{Keywords}

prolylcarboxypeptidase; renin-angiotensin system; kallikrein-kinin system; prekallikrein; high molecular weight kininogen; angiotensin converting enzyme 2

\section{INTRODUCTION}

The renin-angiotensin system (RAS) regulates blood pressure, water and electrolyte balance [1;2]. The RAS has been implicated as a major effector of hypertension and other cardiovascular diseases arising from its production of angiotensin II (Ang II) and angiotensin III (Ang III) [3]. Angiotensin II can be metabolized by at least 13 proteases, among which are angiotensin converting enzyme 2 (ACE2) and prolylcarboxypeptidase (PRCP) which convert Ang II to angiotensin 1-7 (Ang 1-7) [4]. ACE2 and PRCP are switches that transform this peptide from a vasoconstrictor to a vasodilator. Ang (1-7) may act in a synergistic manner to modulate bradykinin-induced vasodilation at the local level. In doing so, ACE2 and PRCP

\$Please Address Correspondence to: Zia Shariat-Madar, The University of Mississippi, 317 Faser Hall, University, MS 38677-1848, 662-915-5150 (tel), 662-915-5148 (fax), email: madar@olemiss.edu.

Publisher's Disclaimer: This is a PDF file of an unedited manuscript that has been accepted for publication. As a service to our customers we are providing this early version of the manuscript. The manuscript will undergo copyediting, typesetting, and review of the resulting proof before it is published in its final citable form. Please note that during the production process errors may be discovered which could affect the content, and all legal disclaimers that apply to the journal pertain. 
regulate the blood flow through active tissues in order to preserve the internal environment [5]. Thus, ACE2 and PRCP have cardiovascular protective roles [6].

Recently, we found that when the complex of high molecular weight kininogen (HK) and prekallikrein (PK) binds to endothelial cells membranes, $\mathrm{PK}$ is rapidly converted to kallikrein by PRCP. Kallikrein then cleaves HK to liberate bradykinin (BK) which is a potent vasodilator by activating constitutive bradykinin B2- and inducible bradykinin B1 receptors-mediating nitric oxide and prostacyclin formation [7]. The PRCP-dependent BK generating pathway might be considered as an additional negative regulator of the pressor actions of the RAS.

In humans, PRCP has been recognized to have 2 mRNAs, termed as PRCP1 (Gene Bank NP_005131) and PRCP2 (NP_955450). The N-terminus of PRCP is where these isoforms diverge. There is no evidence suggesting whether PRCP2 mRNA encodes a functional protein.

PRCP is a polypeptide that folds back on itself to form a three-dimensional functional structure. The monomeric PRCP has the ability to undergo dimerization yet by an uncharcterized intramolecular mechanism of reaction. The residues involved in proteins dimerization differ from protein to protein. Generally, N-terminal, C-terminal, and transmembrane domains of a variety of proteins are found to be implicated in dimeric interaction [8-10]. The first 539 base pairs on the 5 '-end of PRCP encode the putative transmembrane domain and the non-catalytic region [6]. PRCP1 had less than 30\% similarity with the 3D structures of molecules found in the Protein Data Bank. Hence, it was difficult to guess the critical side chains. Therefore we focused on the functional importance of the N-terminal region of PRCP1 and test its role by site-directed mutagenesis, protein expression, and kinetic assessment.

The present investigation was designed to describe the expression and purification of human PRCP which does not contain the first 539 base pairs on the 5'-end ( $\left.\mathrm{rPCP}_{539-1601}\right)$. The rPRCP $_{539-1601}$ contains the catalytic region and is highly conserved with human PRCP family of enzymes and with PRCP in other species. The $\mathrm{rPRCP}_{539-1601}$ is a N-terminal truncated form ( $\triangle \mathrm{N} 179-\mathrm{PRCP})$, lacking $179 \mathrm{~N}$-terminal residues of PRCP with an apparent molecular mass of $40 \mathrm{kDa}$. The $40 \mathrm{kDa}$ recombinant human PRCP $\left(\mathrm{rPRCP}_{40}\right)$ was characterized with respect to its biochemical and physical properties. Collectively, the metabolism of angiotensin molecules by $\mathrm{rPRCP}_{40}$ brings forth a new understanding into the mechanism of actions of PRCP, therefore allowing better insight into structure-function relationships.

\section{MATERIALS AND METHODS}

\section{Materials}

Schneider insect (S2) cells were purchased from Invitrogen (Carlsbad, CA). Serum free insect cell growth medium was purchased from HyClone (Logan, UT). Diethylaminoethyl (DEAE) cellulose was purchased from Whatman (Fairfield, NJ). SP-Sephadex and all reagents were purchased from Sigma-Aldrich (St. Louis, MO). Angiotensin III, angiotensin 1-7, angiotensin I, H-Ala-Pro-pNA, and z-Pro-Pro-aldehyde-dimethyl acetate (Z-Pro-Prolinal) were purchased from Bachem (King of Prussia, PA). Angiotensin 2-7 was obtained from New England Peptide LLC (Gardner, MA). phenylmethylsulfonyl fluoride (PMSF) was obtained from Calbiochem (San Diego, CA).

\section{Expression and purification of wild-type and the mutant PRCP}

In the past, the wild-type PRCP ( $\left.\mathrm{rPRCP}_{52}\right)$ cDNAs has been incorporated into pMT/BIP/V5HisC inducible/secreted expression vector and expressed in Schneider (S2) insect cells [11]. Therefore, we used the same strategy to clone and express a variant cDNA that deleted a sequence of 539 base pairs on 5 -terminal $\mathrm{PRCP}_{539-1607} \mathrm{cDNA}$ into pMT/BiP/V5. The sense primer contained a $5^{\prime}$-encoding sequence $\left(5^{\prime}\right.$ - 
GAA.TTT.CCT.GAC.ATC.AGA.ACA.AGC.TC - 3') and an EcoR I restriction site at the 5' end. The antisense primer ( $3^{\prime}$-CCG.GAA.TTC.TCA.GTG.CTG.CTT.TCC.TGC.ACT -5') had an $E c o R I$ restriction site at the $3^{\prime}$ end. The EcoR I and EcoRI restriction sites were for direct cloning into the expression vector pMT/BiP/V5-His C (Invitrogen, Carlsbad, CA).

pMT/BiP-PRCP plasmid was expressed according to a previously described method [11]. The fidelity of the cDNA for PRCP was confirmed by DNA sequence analysis. The expressed wildtype (with a predicted molecular mass of about $52 \mathrm{kDa}$ ) and mutant PRCP (with a predicted molecular mass of $40 \mathrm{kDa}$ ) were separated by $10 \%$ reduced SDS-polyacrylamide gel electrophoresis (data not shown). The concentration of rPRCP was calculated by measuring its absorbance at $280 \mathrm{~nm}$ in a $1 \mathrm{~cm}$ pathlength cuvette using an UV-Vis spectrophotometer. The molar extinction coefficient was calculated to be $90,000 \mathrm{M}^{-1} \mathrm{~cm}^{-1}$. Using the BeerLambert Law, the concentration of protein was determined [12].

\section{Circular dichroism (CD) measurements}

Far UV CD spectra and thermal-denaturation experiments were recorded on an AVIV 62D CD spectropolarimeter. Spectra in a $0.05 \mathrm{~cm}$ pathlength cuvette were at room temperature $\left(22^{\circ} \mathrm{C}\right)$ with $9.6 \mu \mathrm{M}$ recombinant PRCP mutant in reaction buffer $(0.01 \mathrm{M}$ sodium acetate, $0.07 \mathrm{M}$ potassium phosphate, and $1 \mathrm{mM}$ EDTA pH 4.8). Spectra in a $1 \mathrm{~cm}$ pathlength cell were at 25 ${ }^{\circ} \mathrm{C}$ with $1 \mu \mathrm{M}$ recombinant PRCP mutant protein in reaction buffer. Angiotensin III was added at $1 \mu \mathrm{M}$ when present. Spectra were not background corrected. The thermal-denaturation experiments were performed in a $1 \mathrm{~cm}$ pathlength cell with a sealed top through which a temperature probe was inserted. Temperature was scanned from 15 to $85^{\circ} \mathrm{C}$ while the $\mathrm{CD}$ signal was monitored at $225 \mathrm{~nm}$. The concentration of recombinant PRCP mutant was at 1 $\mu \mathrm{M}$ in reaction buffer. Data are plotted against the probe temperature.

Data were analyzed using IGOR Pro (ver.4.0; Wavemetrics), with procedure files written inhouse. Temperature induced unfolding transitions monitored by $\mathrm{CD}$ were fit to a two-state unfolding model represented as follows

$$
\text { Native } \leftrightarrow \text { Unfolded }
$$

The equilibrium constant, $K$, is given by

$$
K=\frac{[U]}{[N]}
$$

The mole fraction of the unfolded species is given by

$$
f_{U}=\frac{K}{1+K} ; K=e^{\frac{-\Delta G}{R T}}
$$

The relationship between free energy change and melting temperature is given by the equation shown below

$$
\Delta G=\Delta H_{m}\left(1-\frac{T}{T_{m}}\right)+\Delta C_{p}\left(T-T_{m}-T \cdot \ln \left(\frac{T}{T_{m}}\right)\right)
$$

where $\Delta \mathrm{H}_{\mathrm{m}}$ is the enthalpy of unfolding at the melting temperature, $\mathrm{T}_{\mathrm{m}}$ is the melting temperature and $\Delta \mathrm{C}_{\mathrm{p}}$ is the heat capacity at the melting temperature [13]. Unfolding data from the $\mathrm{CD}$ were fit to Eq 3 and 4 with baseline slopes and intercepts as fitted parameters. 


\section{Kinetic studies}

The rate constants for PRCP substrate were determined for both the wild-type and purified mutant PRCPs in reaction buffer containing $0.01 \mathrm{M}$ Na-acetate, $0.07 \mathrm{M}$ potassium phosphate $\mathrm{pH} 5.8$, at $37^{\circ} \mathrm{C}$. The slope of the initial linear increase in absorbance at $304 \mathrm{~nm} / \mathrm{min}$ was used to determine PRCP activity. Blanks with substrate but no enzyme were run to verify that PRCP activity was measured as opposed to substrate auto-hydrolysis. The blank values were subtracted from those in the presence of enzyme to obtain enzyme catalyzed hydrolysis of the substrate. The Michaelis-Menten constant $\left(\mathrm{K}_{\mathrm{m}}, \mathrm{V}_{\max }\right)$ were calculated from Lineweaver-Burke $(1 / \mathrm{S}$ versus $1 / \mathrm{V})$ plots and verified by Hanes-Woolf ( $\mathrm{S}$ versus $\mathrm{S} / \mathrm{V})$ analysis.

\section{LC-MS Studies}

LC-MS experiments for the analysis of angiotensin III and its metabolites were conducted based on the method of Cui [14], with modification. The instrumentation platform used consisted of a Waters Micromass ZQ single quadrupole mass spectrometer coupled to a Waters 2695 HPLC, controlled by Mass Lynx 4.0 Software. Peptide incubation mixtures were separated on a reverse-phase C18 column (Phenomenex Prodigy, $5 \mu \mathrm{m}$, ODS3, $100 \times 4.6 \mathrm{~mm}$ ) using a mobile phase consisting of water (spiked with $0.1 \%$ formic acid) and $\mathrm{CH}_{3} \mathrm{CN}$ at ambient temperature using a constant flow rate of $0.2 \mathrm{~mL} / \mathrm{min}$. The mobile phase gradient of $5 \%$ $\mathrm{CH}_{3} \mathrm{CN}$ in water was increased linearly to $20 \% \mathrm{CH}_{3} \mathrm{CN}$ from $0-10$ minutes, to $50 \% \mathrm{CH}_{3} \mathrm{CN}$ from 10-25 minutes, and decreased linearly to $5 \% \mathrm{CH}_{3} \mathrm{CN}$ from $25-40$ minutes. Electrospray ionization (ESI) parameters: capillary voltage, $3.2 \mathrm{kV}$; cone voltage, $15 \mathrm{~V}$; extractor, $3 \mathrm{~V}$; desolvation temperature, $250{ }^{\circ} \mathrm{C}$, desolvation gas flow, $400 \mathrm{~L} / \mathrm{h}$, source temperature, $120^{\circ} \mathrm{C}$. LC-MS was performed using both TIC and SIR (single ion recording) mode. Angiotensin III $\left(\mathrm{m} / z 466.4\right.$ [MH] $^{+2}$; Angiotensin III-Phe $\left(\mathrm{m} / z 392.9[\mathrm{MH}]^{+2}\right) .10 \mu \mathrm{L}$ of the incubation mixture containing AngIII and PRCP was diluted with water $(240 \mu \mathrm{L})$ and $5 \mu \mathrm{L}$ of this solution was used for analysis.

\section{RESULTS}

\section{Structure and stability of recombinant PRC}

The CD spectrum of $\mathrm{rPRCP}_{40}$ (Figure 1A) illustrates that it is structured with significant helical content as indicated by local minima at $\sim 220$ and $208 \mathrm{~nm}$. Addition of equimolar levels of Ang III did not change the spectrum. Thermal denaturation of $\mathrm{rPRCP}_{40}$ is shown in (Figure 1B). The transition appears to be biphasic illustrating that unfolding occurs in a multistep process. Data were modeled as a simple 2-state transition (Eq 1) to provide estimates of the enthalpy of unfolding and melting temperature. Fits to $\mathrm{Eq} 2$ and 3 resolved an enthalpy change upon unfolding of $33 \pm 1 \mathrm{kcal} / \mathrm{mol}$ and $\mathrm{T}_{\mathrm{m}} 35.3 \pm 0.2^{\circ} \mathrm{C}\left(\Delta \mathrm{C}_{\mathrm{p}}\right.$ was fixed to $\left.0 \mathrm{cal} / \mathrm{molK}\right)$. The enthalpy change resolved from a fit to a 2 -state model less than the enthalpy for the individual fits to a 3 state transition. There was significant change in the $\mathrm{CD}$ spectrum after heating. Figure $1 \mathrm{C}$ shows a comparison of the spectra of PRCP with Ang III added to before and after a themaldenaturation experiment. These data suggest that the unfolding of $\mathrm{rPCP}_{40}$ was irreversible even in the presence of Ang III.

To determine whether $\mathrm{rPRCP}_{40}$ behaved like native PRCP under steady-state kinetic conditions, we monitored the percent liberation of p-nitroanalide from Ala-Pro-paranitroanalide over a range of temperature with a fixed time and enzyme concentration. The stability of $\mathrm{rPCP}_{40}$ was tested by measuring Ala-Pro-pNA hydrolysis at various temperatures for $1 \mathrm{~h}$. The activity of the $\mathrm{rRCP}_{40}$ increased with assay temperature until the temperature reached $37^{\circ} \mathrm{C} . \mathrm{rPRCP}_{40}$ activity gradually decreased at higher temperature, and became completely inactive, presumably by becoming denatured at temperatures above $60^{\circ} \mathrm{C}$. These experiments along with thermal-denaturation experiments (Figure 1C) support the ideas that the N-terminal of PRCP may be involved in its structural stabilization. 


\section{Kinetic characterization of $\mathrm{rPRCP}_{40}$}

We next determined the kinetic parameters of $\mathrm{rPRCP}_{40}$. The specificity of $\mathrm{rPRCP}_{40}$ was studied by determining the $\mathrm{k}_{\mathrm{cat}} / \mathrm{K}_{\mathrm{m}}$ values for the hydrolysis of Ala-Pro-pNA and angiotensin molecules substrates. Linearity of the reaction with time and amount of enzyme was determined in all experiments performed in this study. The rate of hydrolysis of Ala-Pro-pNA by $\mathrm{rPRCP}_{40}$ was plotted as a function of substrate concentration and is shown in (Figure 2). A hyperbolic dependence was observed for $\mathrm{rRCP}_{40}$, consistent with Henri-Michaelis-Menten kinetics, using Ala-Pro-pNA. $\mathrm{rPRCP}_{40}$ like $\mathrm{rPRCP}_{52}$ as shown previously metabolized AlaPro-pNA in a dose- and time-dependent fashion (Figure 2A)[11]. The ratio of enzyme-tochromogenic substrate was adjusted so that the rate of paranitroanalide release was linear over the course of the assay. The $\mathrm{K}_{\mathrm{m}}$ of $\mathrm{rPRCP}_{40}$ and of wild type $\mathrm{rPRCP}\left(\mathrm{rPRCP}_{52}\right)$ for Ala-PropNA was $1.5 \pm 0.4 \mathrm{mM}$ and $3.1 \pm 0.3 \mathrm{mM}$ respectively. The catalytic efficiency $\left(\mathrm{k}_{\text {cat }} / \mathrm{K}_{\mathrm{m}}\right)$ of the $\mathrm{rPRCP}_{40}$ protein towards Ala-Pro-pNA is $18.6 \pm 3.4 / \mathrm{sec}$. To demonstrate that Ala-PropNA hydrolysis was not due to the activities of aminopeptidases and cathepsins, $\mathrm{CdCl}_{2}(3 \mathrm{mM})$, 1,10 phenanthroline $(10 \mathrm{mM})$ and cystatin $(1 \mu \mathrm{M})$, inhibitors of aminopeptidases $\mathrm{A}$ and $\mathrm{N}$, cathepsin $\mathrm{B}, \mathrm{H}$ and $\mathrm{L}$ were added to the incubation cocktail. Our results suggested that the ability of $\mathrm{rPRCP}_{40}$ to hydrolyze the substrate was significantly improved in comparison to $\mathrm{rPRCP}_{52}(\mathrm{p} \leq 0.05)[11]$.

Recently, we showed that Ang II causes substrate inhibition of native endothelial PRCP and rPRCP $_{52}$ [11;15]. To further characterize $\mathrm{rPRCP}_{40}$, substrate inhibition studies were performed. In the substrate inhibition studies, Ang III (a PRCP substrate), but not Ang1-7 (as control) inhibited $\mathrm{rPRCP}_{40}$ in a dose dependent manner suggesting the functional similarity of $\mathrm{rPRCP}_{40}$ with the native endothelial PRCP (Figure 2B) [[15]]. The effect of Ang II precursor, angiotensin I (Ang I) on $\mathrm{rPRCP}_{40}$ was determined. Ang I inhibited PRCP in a dose-dependent manner with an $\mathrm{IC}_{50}$ of $1 \mathrm{mM}$ in the presence of $3 \mathrm{mM}$ chromogenic substrate (Figure 2C).

For the first time, we developed a new and an accurate assay to determine PRCP catalytic activity. The reaction products from the conversion of Ang III, Ang 2-7, and Ang I by $\mathrm{rPRCP}_{40}$ were determined by LCMS. Reaction mixtures lacking enzyme served as negative controls, while $\mathrm{rPRCP}_{40}$ in the presence of the substrate was used as a positive control. As shown in (Figure $4 \mathrm{~A}), \mathrm{rPRCP}_{40}$ has the ability to convert Ang III ( $\mathrm{Arg}^{2}-\mathrm{Val}^{3}{ }_{-}{ }^{125} \mathrm{I}_{-} \mathrm{Tyr}^{4}-\mathrm{Ile}^{5}$ $\left.\mathrm{His}^{6}-\mathrm{Pro}^{7}-\mathrm{Phe}^{8}\right)$ to Ang 2-7 ( $\left.\mathrm{Arg}^{2}-\mathrm{Val}^{3}{ }^{3}{ }^{125} \mathrm{I}_{-}-\mathrm{Tyr}^{4}-\mathrm{Ile}^{5}-\mathrm{His}^{6}-\mathrm{Pro}^{7}\right)$ and phenylalanine. Metabolism of Ang III (1 mM) by rPRCP 40 (100 ng) resulted in three major peaks in comparison to the control (no enzyme) (Figure 3A). The unmetabolized amount of Ang III appeared at $31.58 \mathrm{~min}$, whereas Ang 2-7 and phenylalanine appeared at 28.33 and $26.11 \mathrm{~min}$ respectively. Unmetabolized fraction of Ang III by $\mathrm{PRCP}_{40}$ had a similar retention time as the control (Ang III alone) (Figure $3 \mathrm{~A}$ (inset)). This is a novel finding because N-terminally truncated PRCP like that of endothelial PRCP, which is known for its ability to cleave Pro-X bonds to release the C-terminal amino acid [16], can generate identical metabolites (Ang 2-7 and phenylalanine). To determine the generation of potential secondary metabolites, Ang 2-7 or Ang 1-7 were incubated with $\mathrm{rPRCP}_{40}$. No secondary metabolites were formed by $\mathrm{rPRCP}_{40}$ (Figure 3B) in comparison to the control (Figure 4B inset). Similarly, no secondary metabolites were formed when $\mathrm{rPRP}_{40}$ was incubated with Ang1-7 (Figure 3C). Ang 1-7 in the absence of $\mathrm{PPRCP}_{40}$ was used as a negative control (Figure 4C inset). The incubation of $\mathrm{rPRCP}_{40}$ with Ang I (an ACE 2 substrate) resulted in no metabolite generation (Figure 3D). Ang III was used as a standard and shown in (Figure 3E). When a combination of Ang I ( $1 \mathrm{mM}$ ) and Ang III (1 mM) were incubated with $\mathrm{rPRCP}_{40}$, it resulted in the generation of Ang 2-7. However, the level of Ang 2-7 generated by $\mathrm{rPRCP}_{40}$ in the presence of Ang I was significantly reduced, suggesting that Ang I might be the endogenous inhibitor of PRCP (Figure 3F). These data suggested that the main products of Ang III or Ang II metabolized by $\mathrm{PRCP}_{40}$ are Ang 2-7 and phenylalanine or Ang 1-7 and phenylalanine respectively. 


\section{DISCUSSION}

In view of the role of PRCP in RAS and KKS pathways, investigations were performed to characterize molecular structure and function analysis of recombinant PRCP on the metabolism of Ang III and Ang II. To our surprise, the enzymatic properties of $\mathrm{rPRCP}_{40}$ and mature $\mathrm{rPRCP}_{52}$ characterized in the present investigation indicate that the two proteins have similar functional activities on Ang II and Ang III.

$\mathrm{rPRCP}_{40}$ was tested for its ability to metabolize Ala-Pro-pNA, as well as Ang II and Ang III. The affinity for Ala-Pro-pNA for $\mathrm{rRCP}_{40}$ was higher than for the wild type enzyme. The hydrolysis of substrate by $\mathrm{rRCP}_{40}$ followed Michaelis-Menten kinetics with the $\mathrm{K}_{\mathrm{M}}$ value decreased by a factor of two when compared with the wild type. The catalytic efficiency of $\mathrm{rPRCP}_{40}$ was approximately two-fold higher than the wild type. In substrate inhibition studies, Ang III but not Ang 1-7 in increasing concentration blocked Ala-Pro-pNA hydrolysis.

Angiotensin converting enzyme 2 (ACE 2) forms angiotensin 1-9 from angiotensin 1 (Ang 1). Ang I blocked both Ala-Pro-pNA metabolism (Figure $2 \mathrm{C}$ ) and Ang III metabolism (Figure 2 F), suggesting that it may be an endogenous inhibitor of PRCP.

The most prominent effect caused by extended incubation of Ang III with PRCP is a near total inactivation of Ang III which eliminates its ability to cause $\mathrm{AT}_{1}$ receptor stimulation (Figure 3A). PRCP converted Ang III to Ang 2-7 with no other metabolites being observed.

The temperature inactivation and inhibition studies confirmed the uniqueness of the $\mathrm{rPRCP}_{40}$ 's function. $\mathrm{rPRCP}_{40}$ was found to be much less stable upon incubation at temperatures higher than $50^{\circ} \mathrm{C}$ than endothelial PRCP as was observed earlier, [16;17]. This finding could only be due to folding nature of recombinant PRCP.

Efficient conversion of Ang II to Ang 1-7 by ACE2 as well as PRCP and Ang III to Ang 2-7 by PRCP are critical on endothelium that are continuously exposed to a variety of vasopressor molecules. Therefore, vasodilation rather than vasoconstriction pathways are favored, sustaining function and preparing endothelium to receive the next wave of vasoconstrictor stimuli. PRCP activity provides a measure of endothelium relaxation capacity due to its ability to initiate nitric oxide and prostaglandin generation via kallikrein generation [7;15]. ACE2 and PRCP are gauges of endothelium relaxation processes.

PRCP is a homodimer and the biochemical and physical nature of this dimerization is not known. It is tempting to speculate that the first 179 residues of $\mathrm{N}$-terminal region of PRCP, which is lacking in $\mathrm{rPRCP}_{40}$ could play an important role in the folding and the dimerization of the polypeptides. Our observation that $\beta$-mercaptoethanol does not reduce substrate hydrolysis indicates that cysteine oxidation may not be involved in $\mathrm{rPRCP}_{40}$-induced substrate hydrolysis. The inability of $\beta$-mercaptoethanol or DTT to inactivate $\mathrm{rPCP}_{40}$ has several implications. First, the PRCP monomer containing the catalytic domain retains the ability to metabolize Ang III and Ala-Pro-pNA. Secondly, dimers of PRCP could be the inactive form. Identification and characterization of yet another unidentified modulator that might regulate the equilibrium between the active monomer and the inactive dimers of PRCP will require further investigations.

In conclusion, the structural basis of how PRCP can bind and selectively metabolize a variety of different peptides and protein is far from clear. The work presented here is the first description of the role of N-terminal region of PRCP in the production of Ang 1-7 and Ang 2-7 using LC-MS. It is also the first demonstration of an instance in which Ang I blocks the conversion of Ang III to Ang 2-7 by PRCP. The data thus suggest that a selective increase in Ang I in plasma may be helpful to prevent hypotensive effects of Ang 1-7, Ang 2-7, and bradykinin through PRCP-mediated PK activation. Despite the incomplete characterization of 
PRCP, we showed that the C-terminal region of the $\mathrm{rRCP}_{40}$ contributes to PRCP's catalytic function, and provided additional experimental evidence for this suggestion.

\section{Acknowledgements}

The authors thank Robert Speth and Vardan Karamyan for discussion. This study was supported by American Heart Association 0330193N and NCRR/NIH P20RR021929 to ZSM.

\section{Reference List}

1. Hall JE. Control of blood pressure by the renin-angiotensin-aldosterone system. Clin Cardiol 1991;14:IV6-21. [PubMed: 1893644]

2. McKinley MJ, Albiston AL, Allen AM, Mathai ML, May CN, McAllen RM, Oldfield BJ, Mendelsohn FA, Chai SY. The brain renin-angiotensin system: location and physiological roles. Int J Biochem Cell Biol 2003;35:901-918. [PubMed: 12676175]

3. Jackson, EK. Renin and Angiotensin. In: Brunton, LL.; Lazo, JS.; Parker, KL., editors. Goodman \& Gilman's The Pharmacological Basis of Therapeutics. McGraw-Hill; New York: 2006. p. 789-821.

4. Karamyan VT, Speth RC. Enzymatic pathways of the brain renin-angiotensin system: unsolved problems and continuing challenges. Regul Pept 2007;143:15-27. [PubMed: 17493693]

5. Flordellis CS, Goumenos D, Kourounis G, Tsementzis SA, Paris H, Vlachojiannis J. The shift in the "paradigm" of the pharmacology of hypertension. Curr Top Med Chem 2004;4:487-498. [PubMed: 14965315]

6. Mallela J, Yang J, Shariat-Madar Z. Prolylcarboxypeptidase: A cardioprotective enzyme. Int J Biochem Cell Biol. 2008

7. Zhao Y, Qiu Q, Mahdi F, Shariat-Madar Z, Rojkjaer R, Schmaier AH. Assembly and activation of HK-PK complex on endothelial cells results in bradykinin liberation and NO formation. Am J Physiol Heart Circ Physiol 2001;280:H1821-H1829. [PubMed: 11247797]

8. Okazaki T, Nagaoka Y, Asami K. Ion channels of N-terminally linked alamethicin dimers: enhancement of cation-selectivity by substitution of Glu for Gln at position 7. Bioelectrochemistry 2007;70:380-386. [PubMed: 16814617]

9. Rodriguez-Zavala J, Weiner H. Role of the C-terminal tail on the quaternary structure of aldehyde dehydrogenases. Chem Biol Interact 2001;130-132:151-160.

10. Zanna PT, Sanchez-Laorden BL, Perez-Oliva AB, Turpin MC, Herraiz C, Jimenez-Cervantes C, Garcia-Borron JC. Mechanism of dimerization of the human melanocortin 1 receptor. Biochem Biophys Res Commun 2008;368:211-216. [PubMed: 18222116]

11. Shariat-Madar Z, Mahdi F, Schmaier AH. Recombinant prolylcarboxypeptidase activates plasma prekallikrein. Blood 2004;103:4554-4561. [PubMed: 14996700]

12. Pace CN, Vajdos F, Fee L, Grimsley G, Gray T. How to measure and predict the molar absorption coefficient of a protein. Protein Sci 1995;4:2411-2423. [PubMed: 8563639]

13. Privalov PL. Stability of proteins: small globular proteins. Adv Protein Chem 1979;33:167-241. [PubMed: 44431]

14. Cui L, Nithipatikom K, Campbell WB. Simultaneous analysis of angiotensin peptides by LC-MS and LC-MS/MS: metabolism by bovine adrenal endothelial cells. Anal Biochem 2007;369:27-33. [PubMed: 17681269]

15. Shariat-Madar Z, Mahdi F, Schmaier AH. Identification and characterization of prolylcarboxypeptidase as an endothelial cell prekallikrein activator. J Biol Chem 2002;277:1796217969. [PubMed: 11830581]

16. Odya CE, Marinkovic DV, Hammon KJ, Stewart TA, Erdos EG. Purification and properties of prolylcarboxypeptidase (angiotensinase C) from human kidney. J Biol Chem 1978;253:5927-5931. [PubMed: 28321]

17. Odya CE, Erdos EG. Human prolylcarboxypeptidase. Methods Enzymol 1981;80(Pt C):460-466. [PubMed: 7341916] 
A

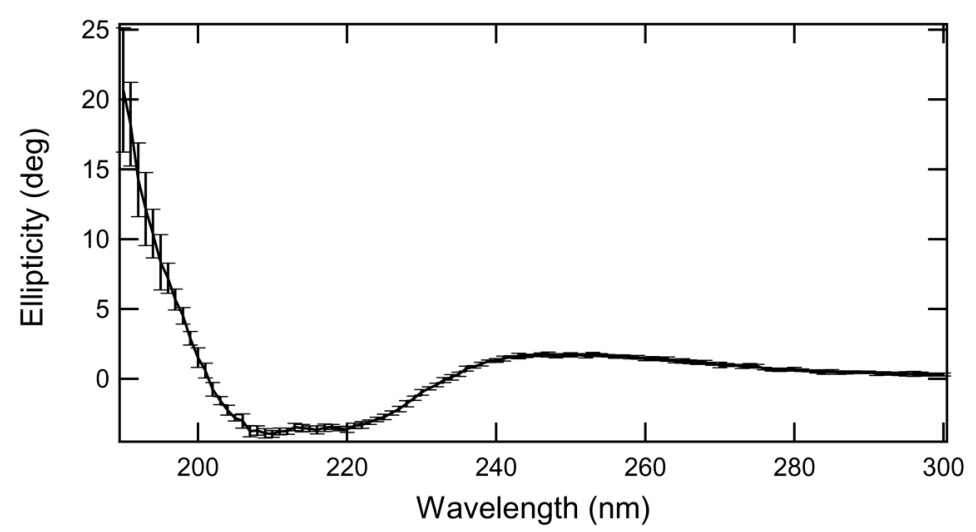

B

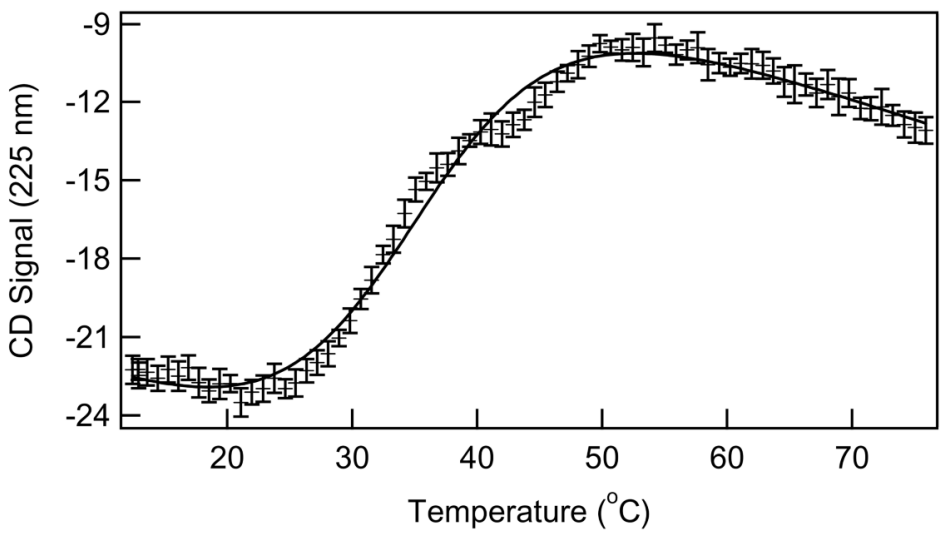

C

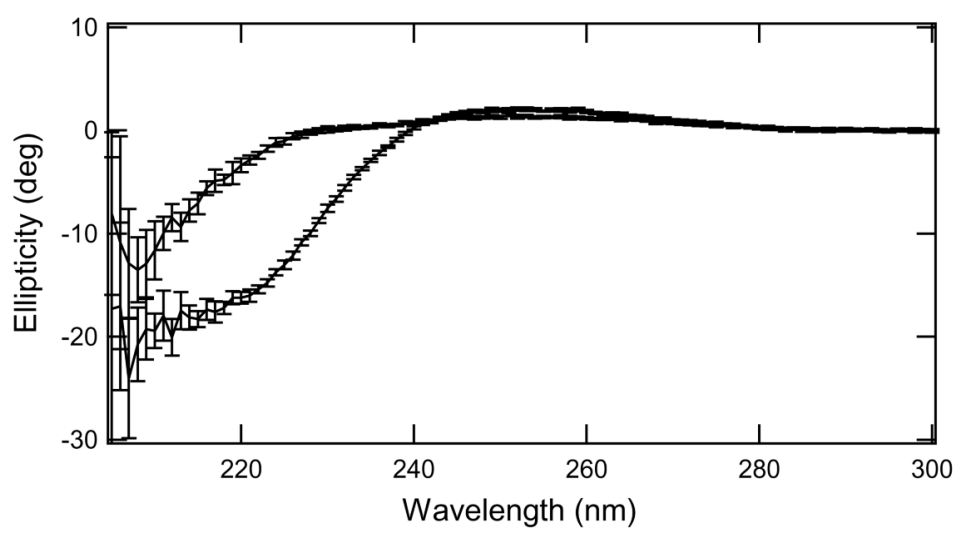

Figure 1.

CD spectroscopy. Panel A. CD spectrum of $\mathrm{rPRCP}_{40}$ at $25{ }^{\circ} \mathrm{C}(0.05 \mathrm{~cm}$ quartz cuvette, 9.6 $\mu \mathrm{M}$ protein). Panel B. Temperature- dependence of molar ellipticity of $\mathrm{rPRCP}_{40}$ at $225 \mathrm{~nm}$. Protein concentration is $1 \mu \mathrm{M}$. Solid line through the data is simulated based on the resolved values to fits to Eqs 4 and 5. The native baseline was fixed to the value resolved for the unfolded baseline. Panel C. CD spectra of $\mathrm{rPRCP}_{40}$ in the presence of $1 \mu \mathrm{M}$ Ang III at $25^{\circ} \mathrm{C}$ before (bottom spectrum) and after (top spectrum) heating to $60^{\circ} \mathrm{C}$. Protein concentration is also 1 $\mu \mathrm{M}$ in a $1 \mathrm{~cm}$ quartz cuvette. (Error bars are one standard deviation of the average value.) 
A.

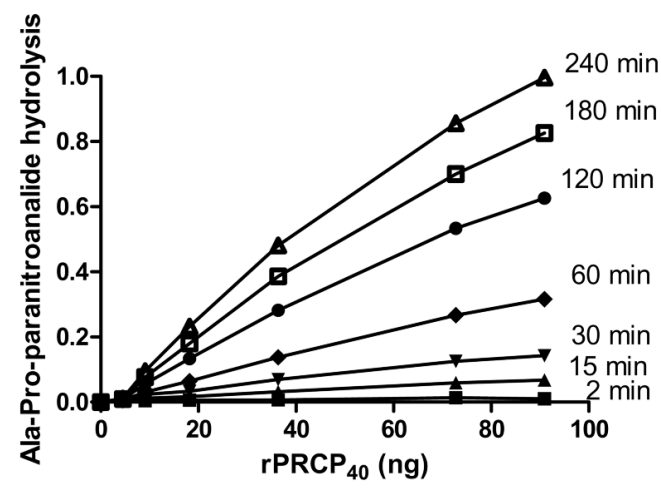

B.

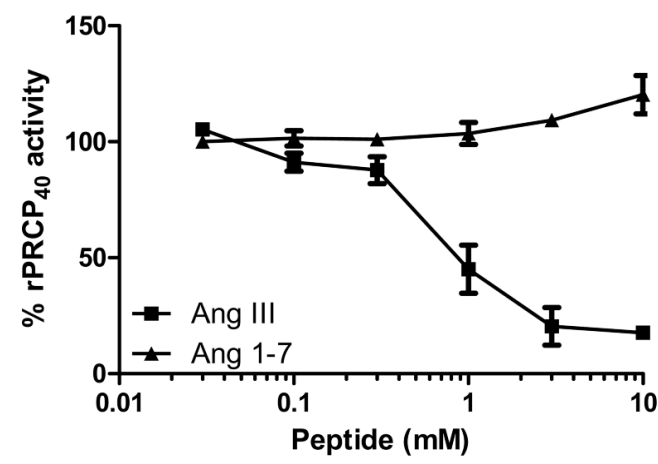

C.

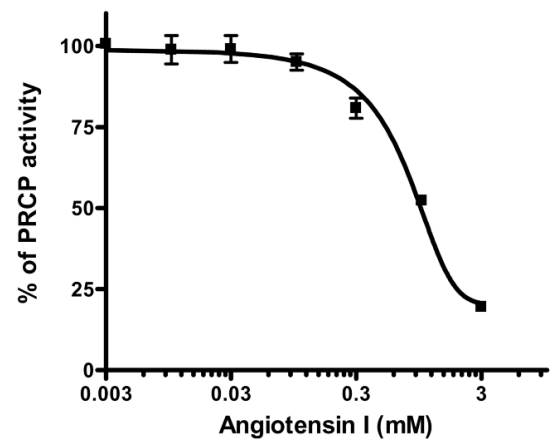

Figure 2.

Enzymatic analysis of $\mathrm{rPRCP}_{40}$. Panel A. Time course and enzyme dependency of $\mathrm{rPRCP}_{40}$ on paranitroanalide generation. The indicated concentration of $\mathrm{rPRCP}_{40}$ was incubated with $1.8 \mathrm{mM}$ Ala-Pro-paranitroanalide (APpNA) in $0.01 \mathrm{M}$ Na-acetate, $0.07 \mathrm{M} \mathrm{KH}_{2} \mathrm{PO}_{4} /$

$\mathrm{K}_{2} \mathrm{HPO}_{4}$ buffer pH 5.8 at $37^{\circ} \mathrm{C}$ for $2(\bullet), 15(\bullet), 30(\bullet), 60(\bullet), 120(\wedge), 180(\square)$, and $240(\Delta)$ minutes and the amount of generated paranitroanalide expressed as OD was assessed for each $\mathrm{rPRCP}_{40}$ concentration. Panel B. Substrate inhibition of $\mathrm{rPRCP}_{40}$. The amount of paranitroanalide formed in the presence of $\mathrm{rRCP}_{40}$ was determined by incubating each well with $1 \mathrm{mM}$ Ala-Pro-paranitroanalide in the absence or presence of increasing concentrations of angiotensin III $(\bullet)$ or angiotensin 1-7 (•). Panel C. effect of angiotensin I (AngI) on 
$\mathrm{rPRCP}_{40} \cdot \mathrm{rPRCP}_{40}$ was incubated with various concentrations of Ang I in the presence of $\mathrm{rPRCP}_{40}$ substrate, Ala-Pro-paranitroanalide (APpNA). Hydrolysis of APpNA was monitored at $405 \mathrm{~nm}$ for 3 hours. The results presented are the mean \pm SEM of three separate experiments and are expressed as $\% \mathrm{rPRCP}_{40}$ activity. 

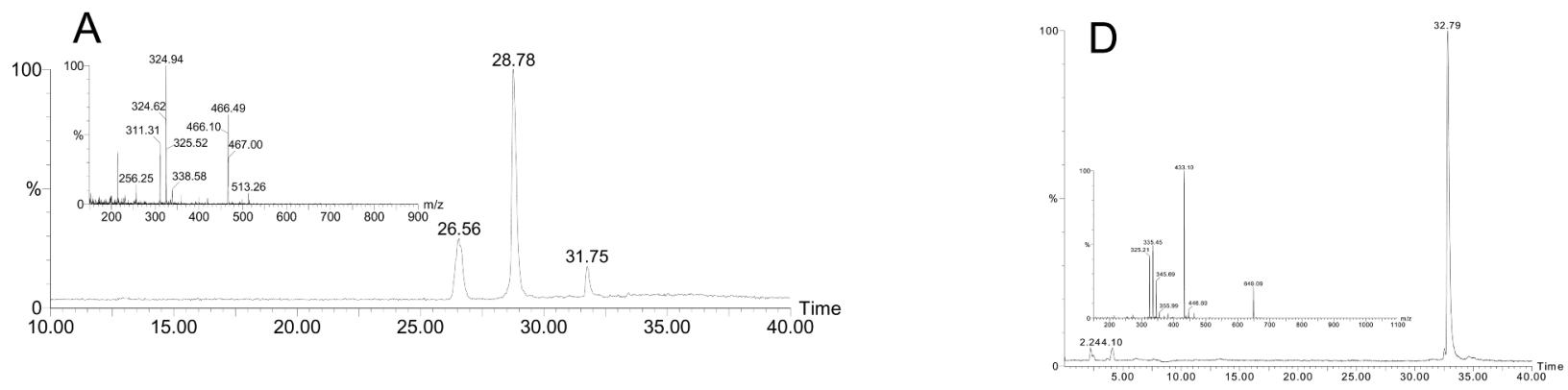

B

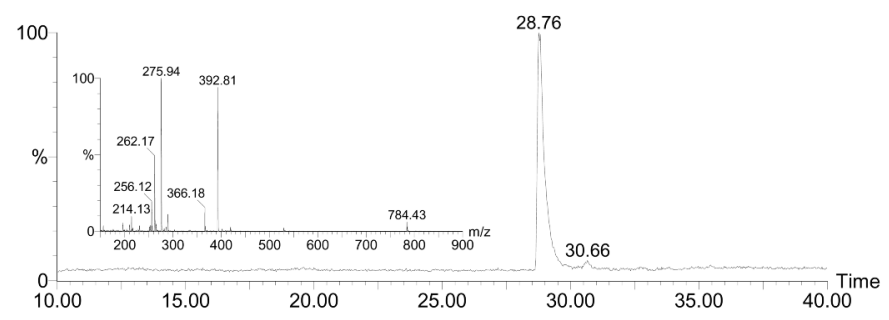

C

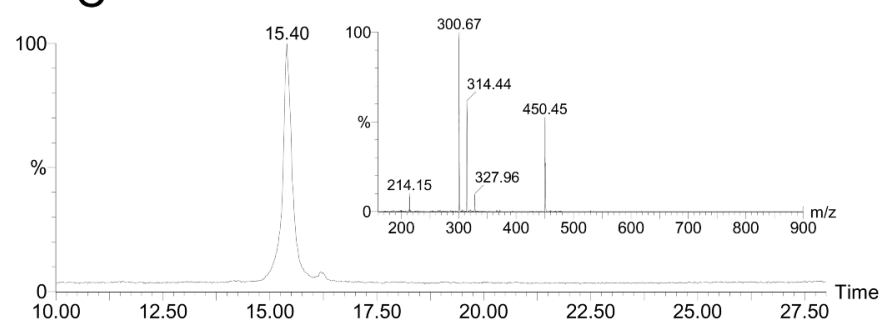

$E$

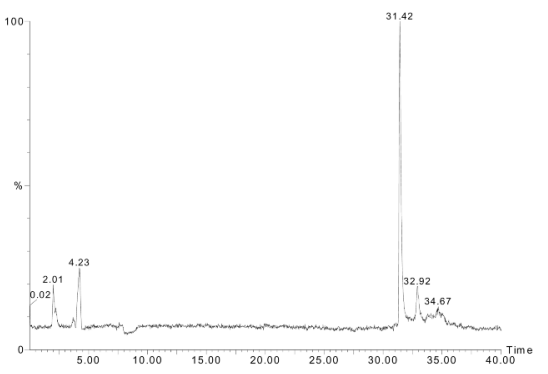

${ }^{100} \mathrm{~F}$

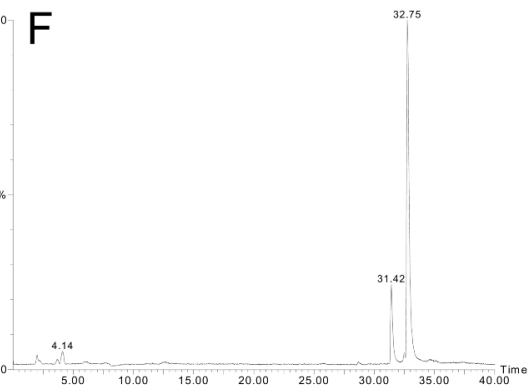

Figure 3.

LC-MS chromatograms of angiotensin peptides. The metabolism of the angiotensin peptides in the absence or presence of $\mathrm{rPRCP}_{40}$ was determined by LC-MS. Panel A, $1 \mathrm{mM}$ angiotensin III (Ang III) was incubated with $100 \mathrm{ng} \mathrm{rPRCP} 40$ for three hours at $37{ }^{\circ} \mathrm{C}$ and the metabolites of angiotensin III were determined and the inset is the Ang III standard mass spectra. Panel B, $1 \mathrm{mM}$ angiotensin 2-7 was incubated with $100 \mathrm{ng} \mathrm{rPRCP} 40$ for three hours at $37{ }^{\circ} \mathrm{C}$ and the metabolites of angiotensin 2-7 were determined. The inset is the mass spectra of Ang 2-7.

Panel C, $1 \mathrm{mM}$ angiotensin 1-7 was incubated with $100 \mathrm{ng} \mathrm{rPRCP}_{40}$ for three hours at $37^{\circ} \mathrm{C}$ and the metabolites of angiotensin 1-7 were determined. The inset is the mass spectra of Ang 1-7. Panel D, $1 \mathrm{mM}$ angiotensin I (Ang I) was incubated with $100 \mathrm{ng} \mathrm{rPRCP} 40$ for three hours at $37{ }^{\circ} \mathrm{C}$ and the metabolites of Ang I were determined. Panel E, Ang III alone was used as standard. Panel F, $1 \mathrm{mM}$ Ang I in combination with $1 \mathrm{mM}$ Ang III was incubated with $100 \mathrm{ng}$ $\mathrm{rPRCP}_{40}$ for three hours at $37^{\circ} \mathrm{C}$ and the metabolites of Ang molecules were determined. 